\title{
Pandemic Minecrafting: an analysis of the perceptions of and lessons learned from a gamified virtual geology field camp
}

\author{
Erika Rader $^{1}$, Renee Love ${ }^{1}$, Darryl Reano ${ }^{2,3}$, Tonia A. Dousay ${ }^{4}$, and Natasha Wingerter ${ }^{5,6}$ \\ ${ }^{1}$ Department of Geography and Geological Sciences, University of Idaho, Moscow, 83843, USA \\ ${ }^{2}$ STEM Transformation Institute, Florida International University, Miami, 33199, USA \\ ${ }^{3}$ School of Earth and Space Exploration, Arizona State University, Tempe, 85281, USA \\ ${ }^{4}$ College of Education, University of Idaho, Moscow, 83843, USA \\ ${ }^{5}$ Water Resources Program, University of Idaho, Moscow, 83843, USA \\ ${ }^{6}$ Red Bluff Fish and Wildlife Office, U.S. Fish and Wildlife Service, Red Bluff, 96080, USA
}

Correspondence: Tonia A. Dousay (tonia@uidaho.edu)

Received: 13 May 2021 - Discussion started: 2 June 2021

Revised: 30 August 2021 - Accepted: 5 September 2021 - Published: 19 October 2021

Abstract. To mimic the 3D geospatial components of geologic mapping usually spotlighted by field camp, we developed a virtual course based in the sandbox video game Minecraft. Paired with audio/video conferencing and real data, students practiced measuring strike and dip, orienteering with a compass, matching landscape features with topographic maps, and tracing geologic contacts within the team structure typically employed in field camp. Open-source programs and tutorials freely available online assisted with constructing the Minecraft worlds. Assignments were aligned to the nine learning outcomes established for geology field camps by the National Association of Geology Teachers (NAGT). A pre-survey and post-survey quantified students' learning of the subject matter as well as perceptions towards Minecraft and online learning. We also held feedback sessions and conducted in-class, live observations to classify students' reactions and experiences during virtual activities. Overwhelmingly, students indicated they would have preferred an in-person field camp, yet they considered the Minecraft assignments exciting, important, interesting, and valuable. Regardless of perceived barriers, scores on subject matter questions increased from the pre- to the postsurvey. Finally, observations illustrated how students' experiences in a virtual field camp recreated comparable components that students experience during an in-person field camp (e.g., students discussing career pathways, geological skills, and fostering interpersonal relationships). Because this virtual course achieved the curricular goals as well as the non- curricular goals and was relatively easy to construct, we recommend the usage of Minecraft for virtual geology courses in the future.

\section{Introduction}

A critical component of nearly all geoscience work is a thorough grasp of spatial concepts (e.g., Black, 2005; Liben and Titus, 2012; Orion et al., 1997). The ability to orient oneself in a landscape, track landforms across great distances, and project complex shapes into the subsurface is a skill many students struggle with initially (e.g., Montello, 2001; Sorby, 2001; Titus and Horsman, 2009). In many geoscience programs, the capstone "field camp" course immerses students in landscapes with their classmates and has been considered the gold standard for producing field-ready geoscientists. Field studies serve as an essential component of scientific curriculum (Fleischner et al., 2017; Lambert and Reiss, 2014). However, what happens when programs suddenly lose access to such experiences as occurred because of the COVID-19 pandemic in the summer of 2020? Some virtual environments, including ours, were developed or augmented during the spring of 2020 (Parcell and Parcell, 2020; Bursztyn et al., 2021; Gregory et al., 2021; Whitmeyer and Dordevic, 2021).

Virtual and augmented realities allow educators to simulate spatial relationships in a scientific context (e.g., Campbell et al., 2002; Elgner et al., 2017; Minocha et al., 2018; 
Moore et al., 1999; Poland et al., 2003; Zhao et al., 2018). In some cases, a virtual rendering of a field site is the only feasible way to explore the area of interest, such as in planetary and oceanographic research (e.g., Anandapadmanaban et al., 2018; Barnes et al., 2018; Elgner et al., 2017; Hodges and Schmitt, 2019; Ortner et al., 2018; Vitacion and Liu, 2019).

Minecraft, in particular, has the potential to help teach students a range of scientific and other academic concepts, some of which may require the manipulation of a spatial dataset. Minecraft can be used to stimulate interest in geology and geography among elementary learners, because it incorporates rich visual simulations (Iwahashi et al., 2019). In addition, mini-games and activities for elementary and secondary learners can integrate all the sciences well, through modeling the earth's surface to support geology and geography visualization of science concepts (Nebel et al., 2016; Short, 2012).

Similar examples include using Minecraft with upper elementary/middle school learners to teach spatial awareness and illustrate interactions between humans and their environment (Scarlett, 2015) or to develop landscape awareness (Sahin and Ozgur, 2016). Formosa (2014) illustrated how recreating cities in Minecraft aids with familiarization prior to traveling. Riordan and Scarf (2016) explored how to use Minecraft to support social interaction and foster collaboration. Building on the success of these previous applications of Minecraft, Clemenson et al. (2019) investigated memory improvement when experiencing rich learning experiences in Minecraft, noting specific benefits to hippocampal memory with implications for enhanced retrieval of information.

One of the Minecraft platform's strengths is the high degree of customization of various geologic elements, such as rock type, rock texture, and tools like compasses or maps (Fig. 1). These capabilities give users the freedom to dig into the subsurface and explore realistic 3D structures from the inside, which can aid student learning. An extensive online community of Minecraft users ("Minecrafters") provides ample resources, tutorials, and open-source code, which the authors utilized to support their novice experience with the game.

Previous research studies focused on the benefits of using Minecraft as a teaching tool have centered on elementary and secondary learners. Post-secondary applications of Minecraft that are documented in discipline-based educational research in the geosciences are scarce. Faced with the challenge of no access to traditional field experiences, the current project drew upon previous recommendations for designing and studying a virtual field experience that incorporated the use of Minecraft. To ensure that the designed virtual field camp had the same educational outcome as traditional (i.e., in-person) field camps, the National Association of Geoscience Teachers (NAGT) put out a set of nine recommended learning outcomes:
1. Design a field strategy to collect or select data in order to answer a geologic question.

2. Collect accurate and sufficient data on field relationships and record these using disciplinary conventions (field notes, map symbols, etc.).

3. Synthesize geologic data and integrate with core concepts and skills into a cohesive spatial and temporal scientific interpretation.

4. Interpret earth systems and past, current, and future processes using multiple lines of spatially distributed evidence.

5. Develop an argument that is consistent with available evidence and uncertainty.

6. Communicate clearly using written, verbal, and/or visual media (e.g., maps, cross-sections, reports) with discipline-specific terminology appropriate to your audience.

7. Work effectively, independently, and collaboratively (e.g., commitment, reliability, leadership, open for advice, channels of communication, supportive, inclusive).

8. Reflect on personal strengths and challenges (e.g., in study design, safety, time management, independent and collaborative work).

9. Demonstrate behaviors expected of professional geoscientists (e.g., time management, work preparation, collegiality, health and safety, ethics).

The virtual field camp (VFC) included assessments aligned to the NAGT outcomes and measured academic effectiveness. Additionally, we strove to mimic positive experiences of in-person field camp, strategically selecting complementary technologies and assignments to supplement Minecraft-based assignments. The nine NAGT outcomes formed the practical framework for an integrated evaluation of the project and the following primary research question. How do students perceive engagement and skill development in a virtual field experience? Connectivism provided a theoretical framework to design and study this innovative learning experience.

A team of seven STEM educators and researchers facilitated this project. Two geoscience instructors co-taught the field experience, designing and implementing all lessons and activities with the assistance of two teaching assistants. Three education researchers collected and analyzed related data.

We had a sample set of 24 enrolled students; $66 \%$ students were working, all were between the ages of 20 and 35,19 of the 24 students identified as White, 6 were female, and 18 were male. The field course was scheduled for 5 virtual days a week and was facilitated using Zoom and 

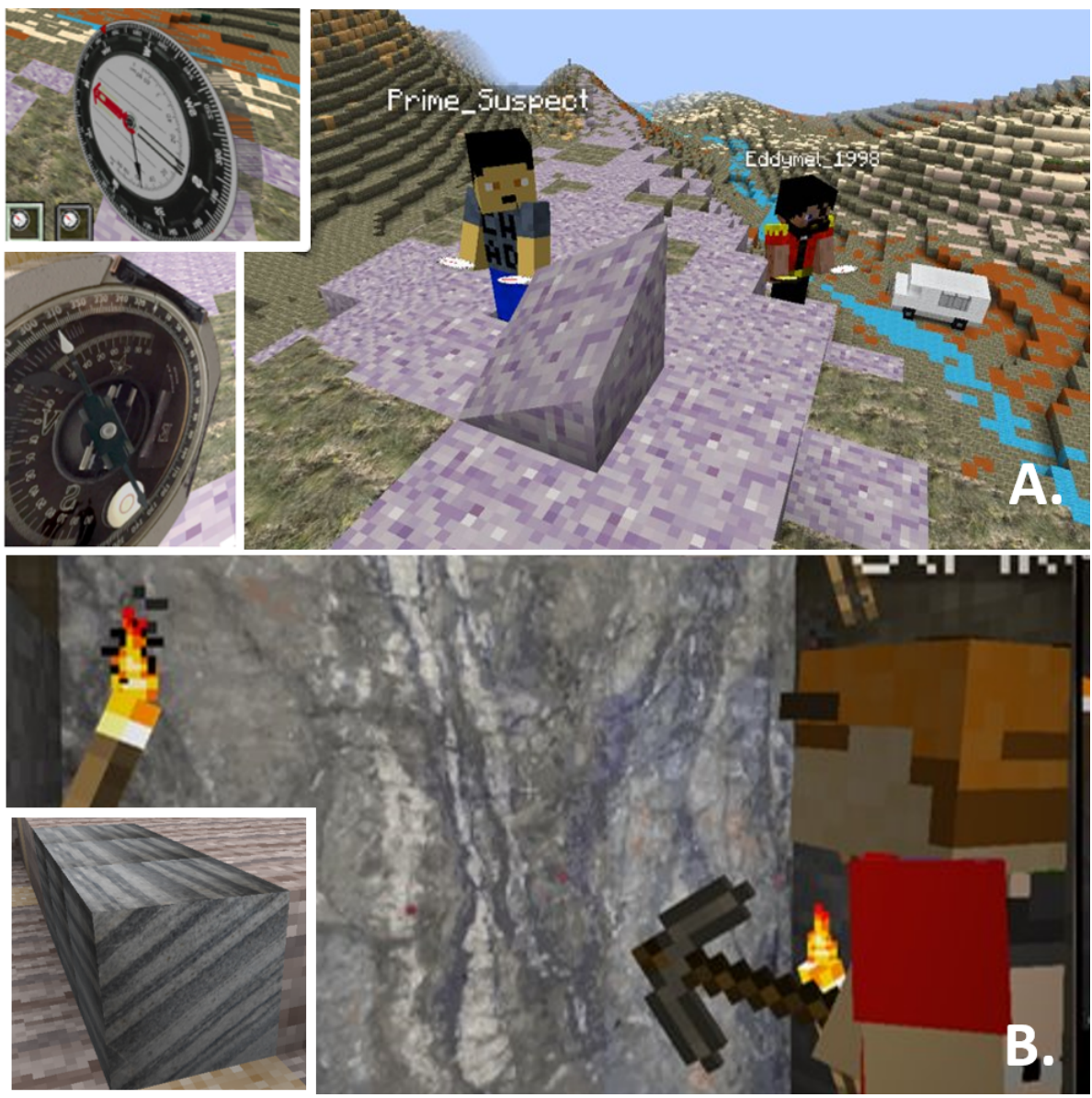

Figure 1. A composite image with panel (a) showing custom compass (insert a) and angled surfaces for measuring strike and dip as well as real photos (b) embedded into the game to provide realistic rock and foliation (insert $\mathbf{b}$ ) identification opportunities.

Blackboard. We began each class with a warm-up exercise to identify features on field photos. This also helped make sure that students came to class on time and allowed us to take attendance. Class was divided into four segments. (1) Morning: this consisted of the morning warm-up, a lecture to introduce key topics and the exercise to be performed, and a question-and-answer session to go over material from the previous day. (2) Mid-morning: if needed, another lecture was presented, but most days students continued on their exercises that began during the morning session or the previous day. This mid-morning check-in allowed the instructors to make sure students understood the exercise material and were working through it in groups. (3) Afternoon: after an hour lunch break, students returned to the Zoom room to get another segment of the exercise, another lecture, or help on the assignment. (4) Evening: instructors and teaching assistants were present on Zoom during the evening for virtual office hours as students completed their assignments. Students were given the weekend to complete mapping projects if needed. Special licenses were obtained for Leapfrog and
Imago before the class began, and servers were set up to facilitate the Minecraft worlds.

\section{Connectivism}

When viewing learning and work in the 21 st century, the connectivism theoretical framework acknowledges that learning is not solitary, and the ways in which we learn and function are influenced by the tools we use. When positing the framework, Siemens (2005) argued that behaviorism, cognitivism, and constructivism theories fail to accurately account for the learning environment and its impact on learner agency and related affective effects. From an educator's standpoint, using an educational environment to enhance learning may seem obvious. However, attributing a measurement of learning to specific aspects of an educational environment is difficult, if not impossible, in contemporary, undergraduate classrooms. To move the theoretical framework forward, Smidt et al. (2017) established a model around connectivism to operationalize how we learn (through connectivist strategies), what we learn (through problem-based scenarios), and why we are learning (contextual application). When innovative learning 
projects apply the connectivist framework, they anchor the learning experience in an active, situated context with authentic elements. For our project, this meant that the education researchers explicitly made connections between the VFC (i.e., educational environment) and the instructor's intentional learning objectives (i.e., the NAGT learning outcomes), student output (e.g., student work products), and observations of student behavior in group work.

The VFC applied connectivism principles through a series of situated lessons and team-based scenarios to support a problem-based learning structure. The underlying principles of connectivism include autonomy, diversity, interactivity, and openness (Downes, 2020). Autonomy recognizes that students have a right to agency, and criticism of connectivism highlights how students do not always benefit from or take advantage of this type of learning freedom. In our project, these principles helped to guide how we measured the success of the VFC situated lessons and team-based scenarios. Kop (2011) noticed that students sometimes lack the selfregulation strategies necessary to succeed in an otherwise independent learning environment that requires design considerations to mitigate isolating aspects.

Individual and collaborative activities and assignments in the VFC capitalized on affordances and mitigated the challenges experienced with connectivism. For example, activities encouraging play and exploration in Minecraft allowed students choice and agency to explore, interact, and form inclusive groups. Further, allowing students the flexibility to customize Minecraft avatar skins provided an outlet for selfexpression. Four exercises placed students into field teams, establishing community and expectations for student engagement, fostering interaction, and supporting autonomy. Students, faculty, and instructional assistants openly communicated using a variety of tools, including a learning management system (i.e., Blackboard), video conferencing, and text messaging.

\section{Curricular design}

\subsection{Turning a geologic map into a mappable Minecraft world}

Numerous free, open-source software packages designed for Minecraft Java Edition (designed by Mojang) aided in recreating the geology, topography, and equipment needed for the VFC. The Tangram Heightmapper (Mapzen, 2017) provided greyscale DEMs of the field locations. Course instructors uploaded these images into World Painter (Pepsoft, 2020) to create the base layer of topography, scaling the images so that students could see enough of the landscape to use topography to orient themselves. An overlay on the geologic map in World Painter allowed the instructors to paint geologic units over the topography with different block types.

In-world design began with sourcing initial block types from BetterGeo, a mod containing more types of rocks and a magnetic compass (Godfirnon et al., 2020). Mods are modified packages that plug into Minecraft Java Edition via the program Forge and allows for customizations in the game. We then created other custom-built block types with Resource Pack Workbench and MrCrayfish's Model Creator (MightyPork, 2018; MrCrayfish, 2020). Custom-built outcrops included inclined surfaces for measuring strike and dip with Carpenter's Block (Mineshopper, 2019), which can create any strike from $0-359^{\circ}$ and dips in any direction from $5-45^{\circ}$. Steeper dips required visual patterns to illustrate bedding, banding, or foliation. Figure 1 depicts a composite illustration of these custom features.

A layer of cover (sand, grass, dirt, etc.) covered the land so that outcrop exposure could be increased or decreased depending on the participants' skill level. Adding plants also mimicked the challenges of mapping in heavily vegetated areas and the benefits when a particular plant corresponds to certain geological features. Modifying the magnetic compass from BetterGeo with Resource Pack Workbench allowed students to read a SILVA Ranger or a Brunton Pocket Transit. A pointing mod enabled avatars to point at outcrops or structures in the game (MrCrayfish, 2020). We added realistic rock faces and "you are here" maps by converting images of rock faces and maps using Image Map (Tryashtar, 2020) to display in frames around the field site.

Students used the mods and resource packs to experience different worlds loaded onto a server. For example, a 3D geologic model published by the British Geological Survey (Entwisle, 2019; Steuer and Thorpe, 2019) contributed to building one of the worlds. We built a small anticline structure with a petroleum play of oil and gas into the West Thurrock model by placing blocks while in the game. We asked students to examine potential surface structures to project into the subsurface, correlate provided geophysical well logs to determine the best target interval and location, and "drill" to test student correlation to find the hydrocarbons. This activity represents the complex and layered approaches to designing activities, ensuring alignment across NAGT learning outcomes.

\subsection{Learning activities}

Each learning activity in the VFC contained multiple exercises targeting specific field or industry skills. In addition to teaching with Minecraft, other technologies assisted with presenting concepts to meet our learning objectives. For example, we designed an industry-focused lesson with multiple exercises to mimic reconnaissance work that mappers at state geological surveys perform before and after visiting a field area. Careful design and structuring of lessons mimicked authenticity and aided with an integrated design.

Across lessons and exercises, we divided students into four teams for activities, including mapping and analysis. In one exercise, students had to work with teams working in adjacent map areas to correlate units and resolve differences. We 
extended this exercise by then placing students in a related Minecraft world with a nearby fold-and-thrust belt to work with facies mapping and recognizing folds and thrust faults in the virtual world. Additionally, these two mapping areas had the same units, providing students with multiple examples of what the rocks looked like in outcrop when exploring the Minecraft block textures.

We used Zoom video conferencing to teach each class, using breakout rooms to facilitate group work. Safety and inclusivity are significant components that students should learn in all field camps. "Safety minutes" were discussed intermittently throughout the course to cover potential hazards if they were mapping in the field, ergonomic concerns, and safety in groups. We also discussed inclusivity in the geosciences (Carabajal, 2017) with a particular focus on fieldwork and the inequities people of color experience in the geosciences (Feig et al., 2019; Marín-Spiotta et al., 2020).

\subsection{VFC lessons}

Four Minecraft lessons framed the VFC experience. Refer to Table 1 for a summary of all lessons, exercises, and components. The first lesson, "the data", reviewed introductory concepts learned in previous courses. Exercise components included reviewing rock identification, notebook essentials, rock orientation, map patterns and contacts, and accurate cross-sections. Lesson 2, "orienting and mapping in Minecraft", focused on orienting in the virtual worlds and completing a simple mapping exercise. The first Minecraft world introduced students to navigating with a paper topographic map and the in-game compass. This exercise, called "orienteering", sent students searching for treasure (a chest buried one block deep) at each station, which required them to be very accurate with their pace and compass technique. Twenty-four chests, buried in rock blocks instead of soil or grass blocks, primed the students for outcrop identification in later worlds. Ten different traverses, generated using a bearing and azimuth conversion spreadsheet, assured students found a unique list of hidden items. The second Minecraft world included in this lesson, "Rochester Minecraft", helped students practice taking strike and dip in Minecraft using either a virtual SILVA or Brunton compass, recognize and draw mapping contacts, identify structures, and construct a final cross-section. Students submitted hard copies of each of these completed maps as deliverables.

Lesson 3, "industry", combined Minecraft with other applications and tasks to provide students with experiences often encountered by professional geoscientists. The "Hecla exercise" used images of core, geochemistry data and face photos of underground mine shafts from the Lucky Friday Mine provided by the Hecla Mining Company in northern Idaho. Using Imago core logging software, students successfully identified rocks, sedimentary structures, and facies changes. Each student logged $\sim 100 \mathrm{~m}$ of core. This software allowed for the identification of target intervals and correla-

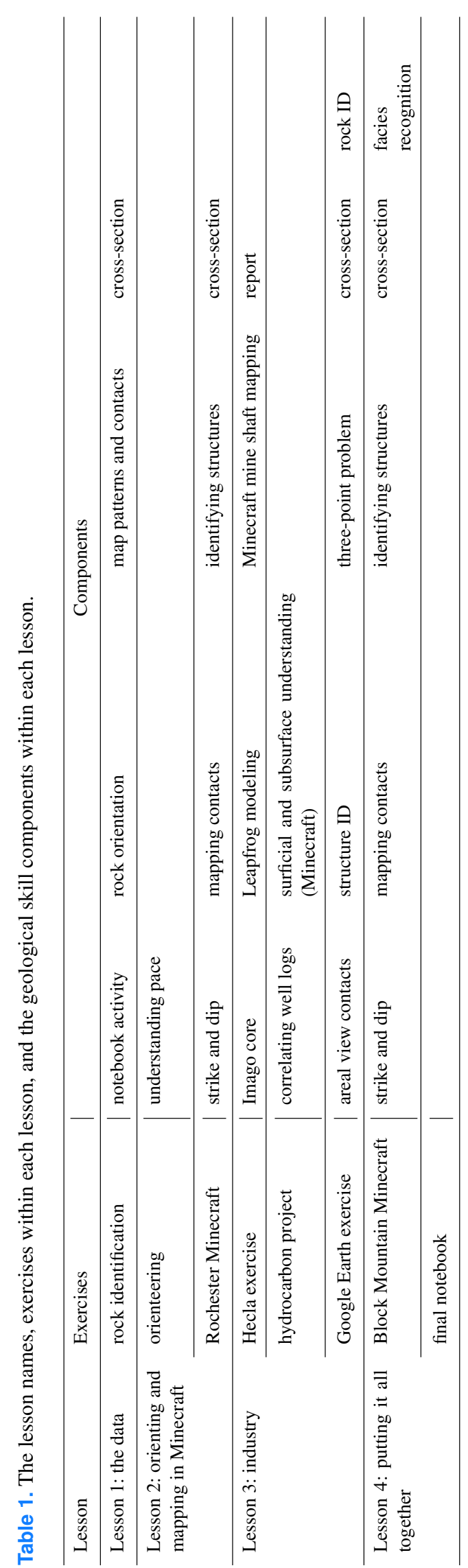

Geosci. Commun., 4, 475-492, 2021 
tion to other students' logs in real-time. The lithologic interpretations of the entire class of the $\sim 20$ cores (collars) were pooled together and exported into a comma-separated value file. The students imported these data into the Leapfrog Geo program. Using all the logged cores from each student, they followed detailed instructions to create a 3D model of the subsurface's main target vein. Students then measured the vein and described a blasting plan.

A continuation of the Hecla exercise sent students underground in our Minecraft mine shaft to map the vein and project which direction to focus drilling next. Students mined in the underground Minecraft world in $2.5 \mathrm{~m} \mathrm{(8ft)} \mathrm{increments}$ with only the 3D model they built to guide them digitally. We placed digital images of real face photos in Minecraft, and as students mapped in the subsurface Minecraft world, they saw whether the face photos lead them to the same answer as their projected Leapfrog Geo model vein. Students drew a vein map based on the true locations of the Ag-bearing sulfide veins. The final component of this four-part mining exercise, the "decision-making reflection" exercise, required students to read academic articles and learn about the vein they modeled and mapped, reflecting on how their interpretation matched or conflicted with the authors and how their understanding of the vein changed at each portion of the assignment.

The "hydrocarbon project" exercise in lesson 3 involved developing eight geophysical well logs, including gamma ray, resistivity, neutron porosity, and density logs. These well logs matched the Minecraft world constructed by the British Geological Survey, West Thurrock, mentioned earlier. We altered the world by placing surface well locations and an accumulation of oil and gas in a closed anticline in the subsurface. As students interpreted and correlated their geophysical logs, they hypothesized the best location for the hydrocarbon reserves in the subsurface. They also compared locations of the hypothesized target interval to potential surface structures in-world, as potential subsurface trap type may have affected their primary target. After they completed their interpretation of the stratigraphic architecture, identified potential oil-gas-water contacts, and determined which interval would be their largest target, we then opened the Minecraft world for students to drill into the subsurface and test their prediction. Students drilled by breaking blocks in the traditional Minecraft way. Two wells had good target intervals, but students had to think about types of traps in the subsurface and the amalgamation of reservoir sands to select the best target.

The "Google Earth" exercise wrapped up lesson 3 by preparing students for field area reconnaissance, digitally creating contacts using areal observations of the landscape, using petrologic rock identification using location-specific photographs to determine stratigraphic units, and recognizing structural features in map view as they relate to stratigraphy and map patterns. Students also learned how to digitally decipher strike and dip using the Dynamic 3-Point
Geological-Plane Problem Solver (Jamieson and Herman, 2019) and converted their bedding orientation measurements to represent the correct strike and dip symbol using the Orientation Symbol Generator (Whitmeyer, 2021). Students used these strike and dips in determining structures in their final Google Earth map. We based this exercise on imagery in the Sevier fold-and-thrust belt of southeastern Idaho and northwestern Wyoming.

"Putting it all together", the final lesson, encompassed applications of all the skills students learned throughout the VFC into a final Minecraft mapping world. This virtual world simulated a traditional field camp mapping area near Dillon, Montana. Students used the learned skills from previous exercises, including strike and dip, mapping contacts, identifying structures, and constructing a cross-section (Video supplement). Additionally, students had to recognize the units based on facies. Each facies had a specific Minecraft block associated with it, and students had to put the facies in geologic context to determine the correct unit. Students kept a field notebook to record their field observations, location, discussion on hypothesis as they mapped an area, and drawings throughout the course. Students submitted their final notebook at the end of this lesson.

\section{Findings}

\subsection{Data collection}

We used a concurrent mixed methods design (Creswell et al., 2003) to integrate quantitative and qualitative data of our research design (Fig. 2). Students who enrolled in the VFC were asked to complete the surveys before and after the VFC experience. The pre-survey and post-survey designed in Qualtrics collected all the responses. The survey questions were designed to evaluate students' geological knowledge and skills in relation to the nine NAGT learning outcomes, perceived barriers to participation in the VFC, and how students felt about the Minecraft assignments (e.g., ease of communication, technical issues, difficulty of assignments).

Participation in the surveys was voluntary and confidential. Table 2 summarizes the alignment between NAGT learning outcomes, related exercises, and correlating assessment questions. A nonparametric Wilcoxon signed-rank test compared significant differences in skills and knowledge from each student's pre-survey to post-survey. We selected a nonparametric approach as data were left-skewed (R Core Team, 2021). $P$ values of less than 0.05 were determined significant.

Qualitative data collection consisted of participant observations and transcription of participant dialogue during the Minecraft activities. The education researchers conducted naturalistic observations to monitor student teams during exercises for behavioral events with contextual influences during the virtual geologic learning experience, including social and cultural interactions (Angrosino, 2007; Dishion and 
Table 2. Exercises and survey questions that were designed to address the NAGT field camp learning outcomes.

\begin{tabular}{|c|c|c|}
\hline & NAGT learning outcomes & Related exercises \\
\hline 1 & $\begin{array}{l}\text { Design a field strategy to collect or select data } \\
\text { in order to answer a geologic question. }\end{array}$ & Minecraft mapping, Google Earth exercise \\
\hline 2 & $\begin{array}{l}\text { Collect accurate and sufficient data on field re- } \\
\text { lationships and record these using disciplinary } \\
\text { conventions (field notes, map symbols, etc.). }\end{array}$ & $\begin{array}{l}\text { Notebook exercise; hard copy of map mak- } \\
\text { ing from Minecraft worlds; Google Earth } \\
\text { exercise }\end{array}$ \\
\hline 3 & $\begin{array}{l}\text { Synthesize geologic data and integrate with } \\
\text { core concepts and skills into a cohesive spatial } \\
\text { and temporal scientific interpretation. }\end{array}$ & $\begin{array}{l}\text { Cross-section reconstruction of mapped ar- } \\
\text { eas; subsurface projections of vein mod- } \\
\text { eling and well log correlation; measuring } \\
\text { strike and dip in Minecraft; three-point } \\
\text { problem in Google Earth }\end{array}$ \\
\hline
\end{tabular}

Related survey question(s)

1. When assigned an area to map, what order should you do the following to prepare?

1. Plot the location and structural data on a map using correct symbology.

2. Trace contacts between units and draw in proper structure symbols to explain those contacts.

3. Name as many ways to capture/record your observations (data) in the field as you can think of.

4. What are some ways to present these data as interpretations in a final product (e.g., geologic map)?

1. Correlate the top of the fining-upward and coarseningupward sequences from the geophysical well logs.

2. After correlating the five well sections, use your interpretation to determine the structure(s) in the subsurface. What structure(s) did you identify and in which well(s)?

3. Based on the lithologies and structures in the well logs, how has the basin changed over time? In your answer include both depositional and structural history.

4. In a photo provided, explain some reasons why the geologist who mapped this area put the thrust faults in those locations.

5. Describe how you were able to practice and apply spatial and geologic mapping skills in the course learning activities?

4 Interpret Earth systems and past, current, and future processes using multiple lines of spatially distributed evidence.
Geophysical well log correlation; core logging; structural interpretation of mapped ar eas
1. Use your map to deduce the geologic history of (this) area. Which of the following events occurred or did not occur (metamorphism, erosion, faulting, etc.)?

2. What are some characteristics of rocks used to distinguish between units out in the field?

1. Review the incomplete geologic field map with three sections missing. Based on data surrounding the gaps, choose an area that you would visit again to collect more data. Why did you choose this area? Describe what you expect the geology is doing in that area and why. Propose an alternative hypothesis.

1. When making your map, what geological principles, rules, laws and techniques did you use to determine the geologic structures, unconformities, and correct stratigraphic positioning on a map and what principles would you use to extrapolate these features in the subsurface?

1. Describe how connected or disconnected you felt with the learning experience in this field camp course.

2. Describe how you feel your team building and related activities went in this field camp course. What worked well? What did not work well?

1. What problems or challenges did you experience with respect to accessing and using technology for this field camp course?

2. Compared to traditional field camp experiences, the Minecraft-based camp was [more/less] engaging?

1. What are some safety risks involved in field work?

2. Have you thought of additional personal barriers or challenges that you perceive and experience as a student interested in the geosciences?
Granic, 2004). Additionally, the researchers used a momentary time sampling approach based on the course activity schedule to observe the activities described in the previous section, providing a composite picture of students' behavior during the VFC.
We documented comments and observations made during the activities, and two of the education researchers independently coded data for later comparison. One observer per team allowed for simultaneous observations of multiple groups of students. Observers joined the student teams 


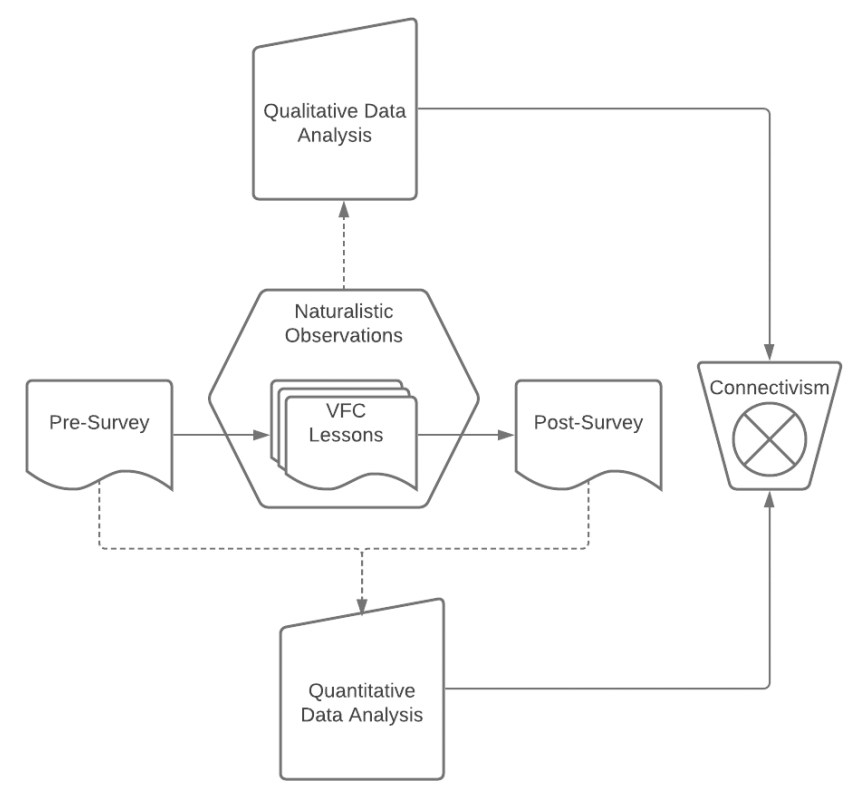

Figure 2. The mixed method study design for the project.

in their Zoom breakout rooms with their camera and microphone off to be less obtrusive. Observers were also logged into Minecraft and followed their assigned team in the game using "spectator mode", a setting that allowed the observers to be invisible to the student teams. This setting also prevented observers from being subject to the same player requirements and restrictions as learners and the ability to fly if separated during exploration.

\subsection{Participant demographics}

All students in this course $(N=25)$ were junior and senior undergraduate students who had previously taken a 3-credit field-based methods course. Prior experiences ensured practice mapping and measuring rock orientation on real rocks in the real world to anchor virtual exercises. Students ranged in age from $21-35$. One student (4\%) identifies as nonbinary/third gender, 5 students $(21 \%)$ identify as female, and 18 students $(75 \%)$ identify as male. Most students were White $(79 \%, n=19)$, two were American Indian/Alaska Native (8\%), one was of Asian (4\%), one was Black/African American (4\%), and one was Hispanic/Latino/Spanish origin $(4 \%)$. During the course, 2 of the students $(8 \%)$ worked at a job more than $30 \mathrm{~h}$ a week, $12(48 \%)$ worked fewer than $29 \mathrm{~h}$ per week, and $11(44 \%)$ did not work at all.

\subsection{Geospatial skill development, barriers, and interest}

\subsubsection{Analysis}

We measured geospatial skill improvement and perceptions of barriers and interest quantitatively with a pre-survey and post-survey. Of the 25 students, 22 provided complete pre- post-survey data for analysis and discussion. Geospatial skill improvement questions assessed students' ability to master traditional field camp skills and concepts. Open-ended questions and related Likert-like statements assessed students' perceptions of barriers. Likert-like statements included a continuum of agreement to experiencing barriers such as non-academic commitments, financial constraints, and preference for a traditional learning environment. We assessed student interest and engagement using the Situational Interest Survey for Multimedia (SIS-M) (Dousay, 2016; Dousay and Trujillo, 2019). Survey questions targeting geospatial skill development took advantage of interactive Qualtrics question types, including heat maps, rank and order, and dragand-drop matching.

We compared pre- and post-survey raw skill scores using a Wilcoxon signed-rank test to determine mean changes in skills among the class using the wilcoxon.test function in $\mathrm{R}$ programming ( $\mathrm{R}$ Core Team, 2021). A nonparametric Wilcoxon approach was chosen to compare the preassessment and post-assessment of skill as an alternative to a Student's $t$ test because it is much more robust to outliers and performance assessments often fail to follow a normal distribution. To control for potential media influence, we compared skill improvement and overall satisfaction of the course with students' familiarity with Minecraft using a KruskalWallis test using the kruskal.test function in $\mathrm{R}$ programming (R Core Team, 2021).

\subsubsection{Results}

Student assessment data indicates a mastery of traditional field camp skills and concepts in a virtual platform, particularly in NAGT learning outcomes (LOs) 2-4. See Table 3 for a summary of exercise alignments with NAGT LOs and the most significant improvements. Scores on NAGT LO 2 (collect accurate and sufficient data on field relationships and record these using disciplinary conventions (field notes, map symbols, etc.)) showed significant improvement in the pre- post-survey question, in which students plotted location and structural data on a map using correct symbology (Wilcoxon signed-rank test, $Z=2.20, p=0.028$ ). Students also improved their identification of ways to capture and record observations in the field and present these observations as a final product (Wilcoxon signed-ranked test, $Z=1.79, p=0.073 ; Z=1.83, p=0.067$ ), though this result was not statistically significant. The survey design used to capture improvements in these skills may have influenced significance as students listed as many examples as possible. Further evaluation into the diversity of responses as a class could be beneficial beyond the raw number of examples in determining skill improvement among students. Scores on NAGT LO 3 (synthesize geologic data and integrate with core concepts and skills into a cohesive spatial and temporal scientific interpretation) also improved. This question asked students to correlate the top of the fining-upward and 
Table 3. NAGT learning outcomes where students showed the most improvement and the corresponding activities that targeted each outcome.

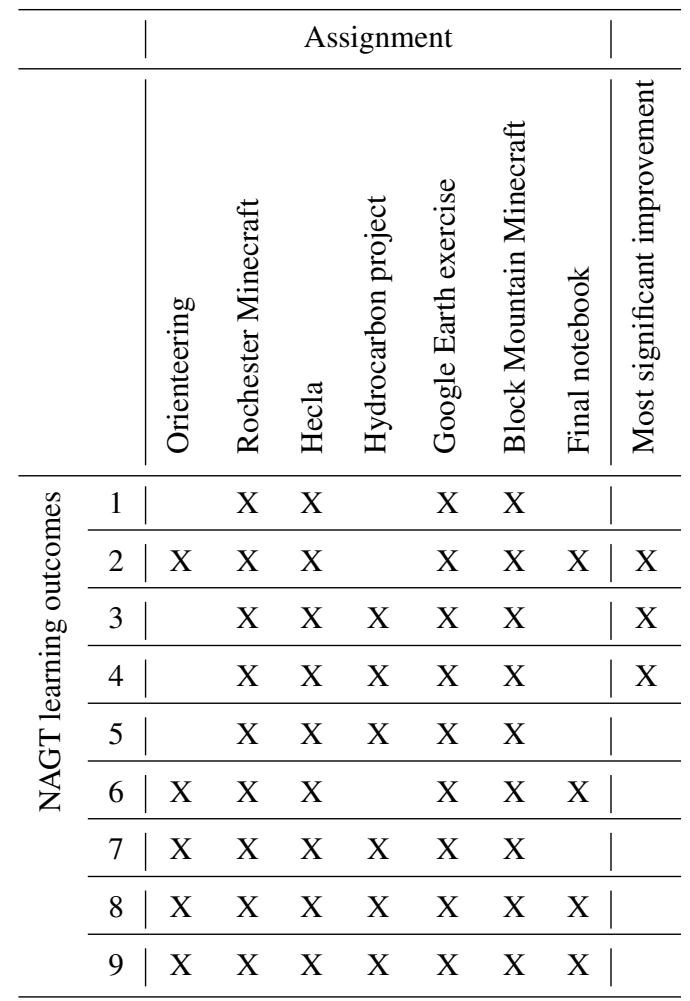

coarsening-upward sequences from geophysical logs and explain possible reasons why the geologist who mapped an area put the thrust faults in respective locations (Wilcoxon signedrank test, fining-upward, $Z=23.09, p=0.002$; coarseningupward, $Z=2.63, p=0.008$; thrust faults $Z=2.11, p=$ 0.035). Finally, scores on NAGT LO 4 (interpret earth systems and past, current, and future processes using multiple lines of spatially distributed evidence), assessed by the ability to correctly name characteristics to distinguish between different units in the field, showed also significant improvement (Wilcoxon signed-rank test, $Z=2.61, p=0.009$ ). Figure 3 illustrates student performance on the hydrocarbon project exercise, highlighting how student responses were much more targeted and correct after completing the VFC.

Interestingly, students' perceived familiarity with Minecraft did not influence overall performance on the presurvey and post-survey (Kruskal-Wallis test $H(4)=3.76$, $p=0.44)$.

Concerning student perceptions, findings highlight the value of a virtual experience and shifting perspectives. Figure 4 illustrates student responses to the SIS-M after completing the VFC. The first four statements of this scale represent triggered interest, or the initiation of interest, and the remaining statements represent maintained interest, or associating the interest with extended value (Dousay, 2016; Hidi and Harackiewicz, 2000). In multimedia learning environments, the goal is to trigger interest, thereby increasing the chances of finding value and meaning in the learning experience (Trujillo and Dousay, 2014). Student responses indicate that the VFC strongly triggered their interest, with most students agreeing or strongly agreeing to the first three statements (Fig. 3). We posit that responses on the fourth statement skew towards undecided because the students knew that the experience was a substitution and therefore inherently less exciting.

To control for potential media bias in responses, we also assessed student preferences concerning using Minecraft and online learning (see Fig. 5). The Minecraft environment was not less well-received nor less effective with students who preferred an in-person field camp, which was most of the students.

Lastly, we asked students to share their perceptions of barriers to success they faced in completing the VFC. Figure 6 illustrates how students responded to the pre-survey, which included barriers to participation in a traditional field experience. Notably, students commonly perceived financial impacts as a barrier to participation in a traditional field camp and technology as a barrier to participation in the VFC. Content knowledge appeared as a common barrier to participation in both experiences. Figure 7 illustrates student responses to this question reflectively on the post-survey. Notably, 9 students of the 25 indicated experiencing no barriers.

\subsection{Student behavior during the VFC}

\subsubsection{Analysis}

Observers kept running notes, briefly describing participant observations and quotes. Notes captured actions and conversations both in Zoom and Minecraft with running timestamps. Observations differentiated between individual students as well as instructors. The observers compiled notes digitally in Microsoft Excel to prepare for the qualitative analysis. An iterative coding scheme began with open coding of the qualitative dataset, generating 19 exploratory codes for discussion by the three education researchers. Coding occurred in Microsoft Excel using a binary system by two of the education researchers. This process produced eight axial codes leading to identifying five major themes represented in the qualitative dataset. Two of the three education researchers then re-coded the qualitative dataset using the nine NAGT learning outcomes as codes. Three meetings provided an opportunity to discuss observations, resolve codes, and reach a consensus on the themes identified in the data. Comparing the two separate analyses highlighted NAGT learning outcomes representation in the five major themes (see Table 4).

\subsubsection{Results}

Exploratory analysis of the qualitative data resulted in five major themes: skill development, geoscience communica- 


\section{Hydrocarbon Exercise}

\begin{tabular}{|c|c|c|c|c|c|}
\hline & (a) & Prior Assessment & (b) & Post Assessment & \\
\hline $\begin{array}{l}\text { Correlate the } \\
\text { top of the } \\
\text { fining-upwarc } \\
\text { sequences } \\
\text { from well to } \\
\text { well. }\end{array}$ & 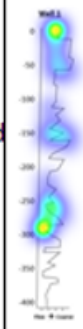 & 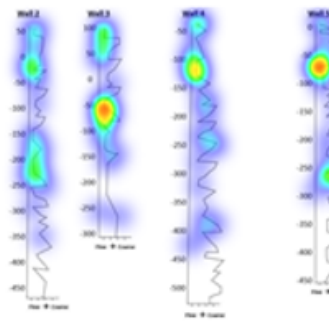 & 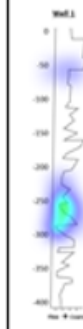 & 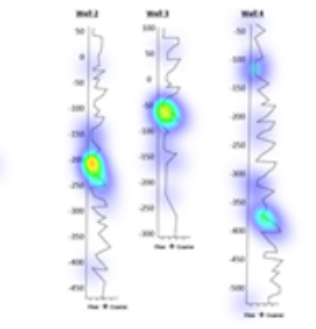 & 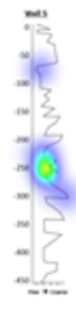 \\
\hline $\begin{array}{l}\text { Correlate the } \\
\text { top of the } \\
\text { coarsening- } \\
\text { upward } \\
\text { sequences } \\
\text { from well to } \\
\text { well. }\end{array}$ & 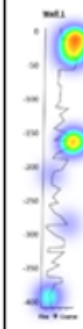 & 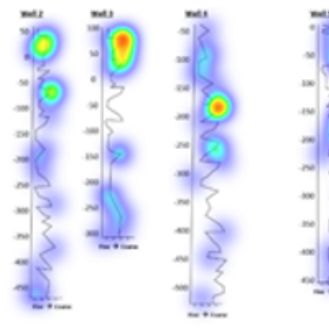 & 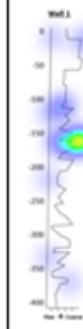 & 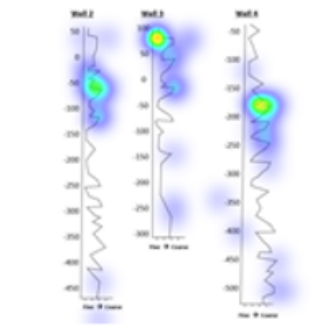 & 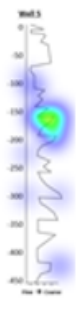 \\
\hline
\end{tabular}

Figure 3. An example heatmap question from the pre-survey (a) and post-survey (b) illustrating the improvement of students' ability to select the correct location of sedimentary features from a geophysical well log. Note that the post-survey indicated more targeted answers than the pre-survey.

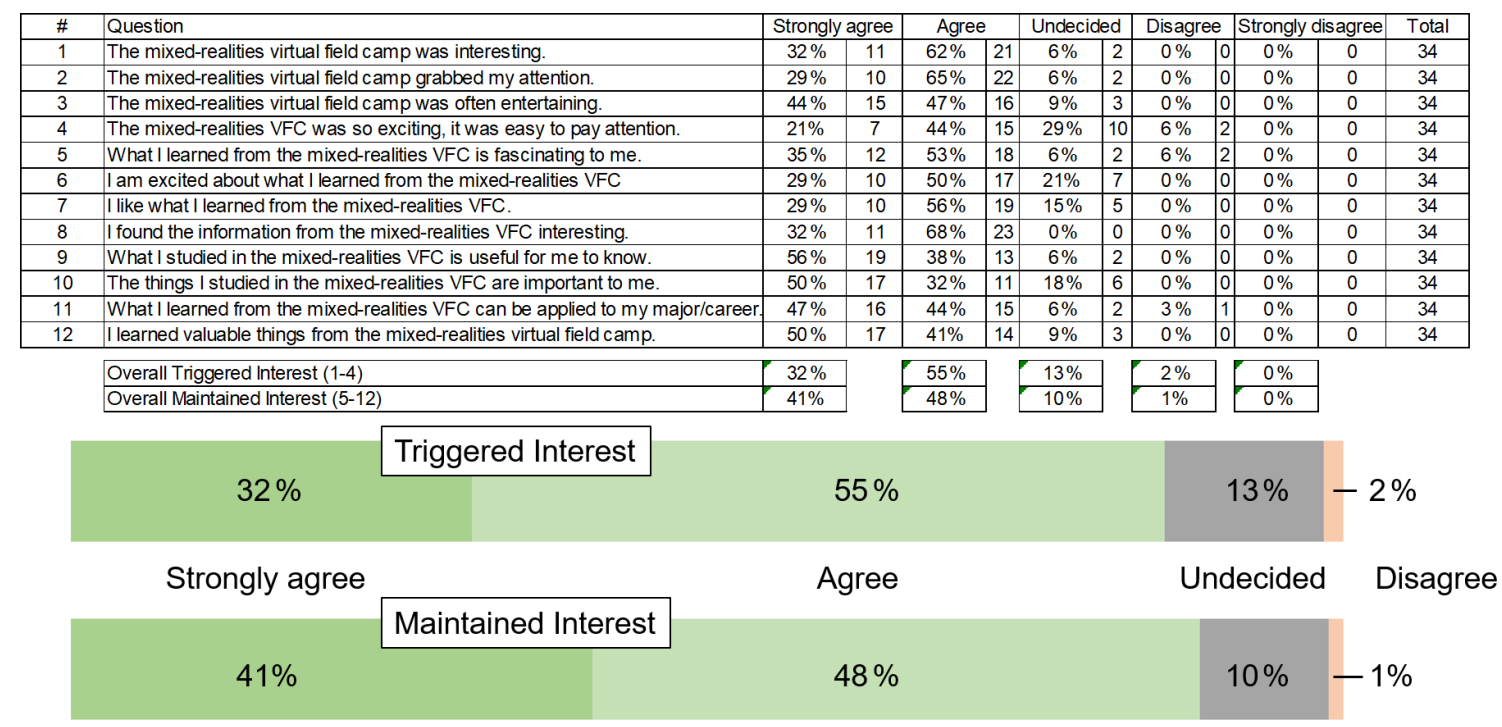

Figure 4. Evaluations of students' perception of the value of the virtual field camp were overall very positive. Students agreed or strongly agreed with a variety of statements that assessed positive interest and engagement.

tion, team dynamics, barriers, and professional motivation. In the following paragraphs, we briefly define each theme, explain correlating NAGT learning outcomes, and share representative data of each theme.

The "skill development" theme emerged through dialogue or observations of students demonstrating knowledge of technology or geoscience content. Subcodes for this theme included "geoscience content knowledge" and "technical knowledge". Data analysis correlated NAGT LOs 1-4 with this theme. Examples of this theme included "I'm just trying so that if I see it again, I know what the vein looks like", "The legend might lump units on one part of the map as opposed to other areas that they separate", "I thought the traverse was a lot of fun and good practice for using Minecraft 

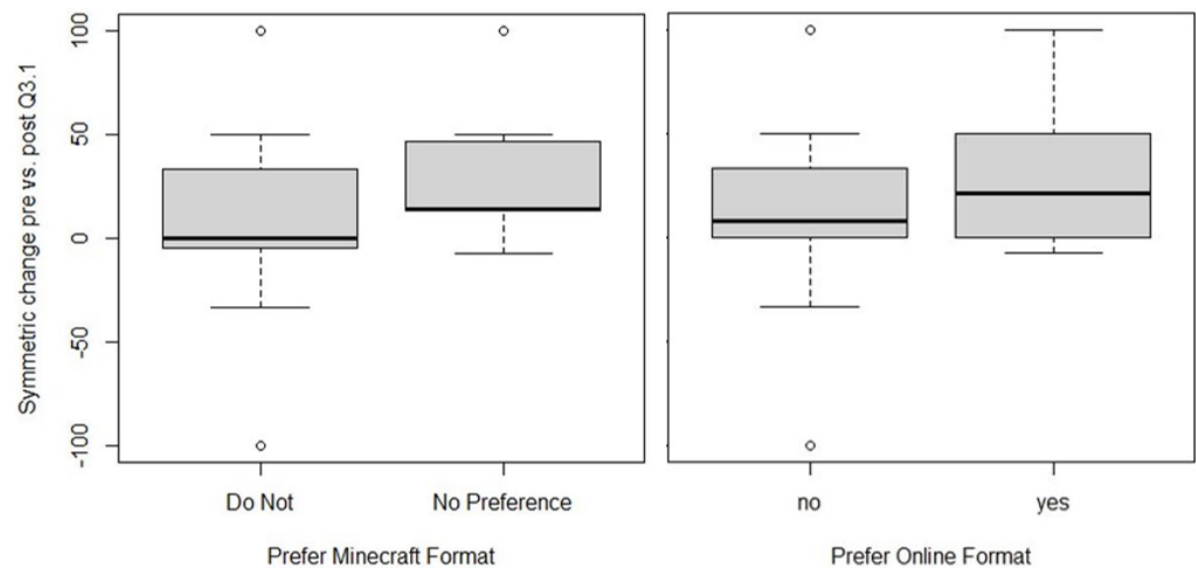

Figure 5. Students who did not prefer the online or Minecraft format of class improved by similar amounts as the rest of the students.

\section{$\underline{\text { Student identified common barriers to success-Before Virtual Field Camp }}$}

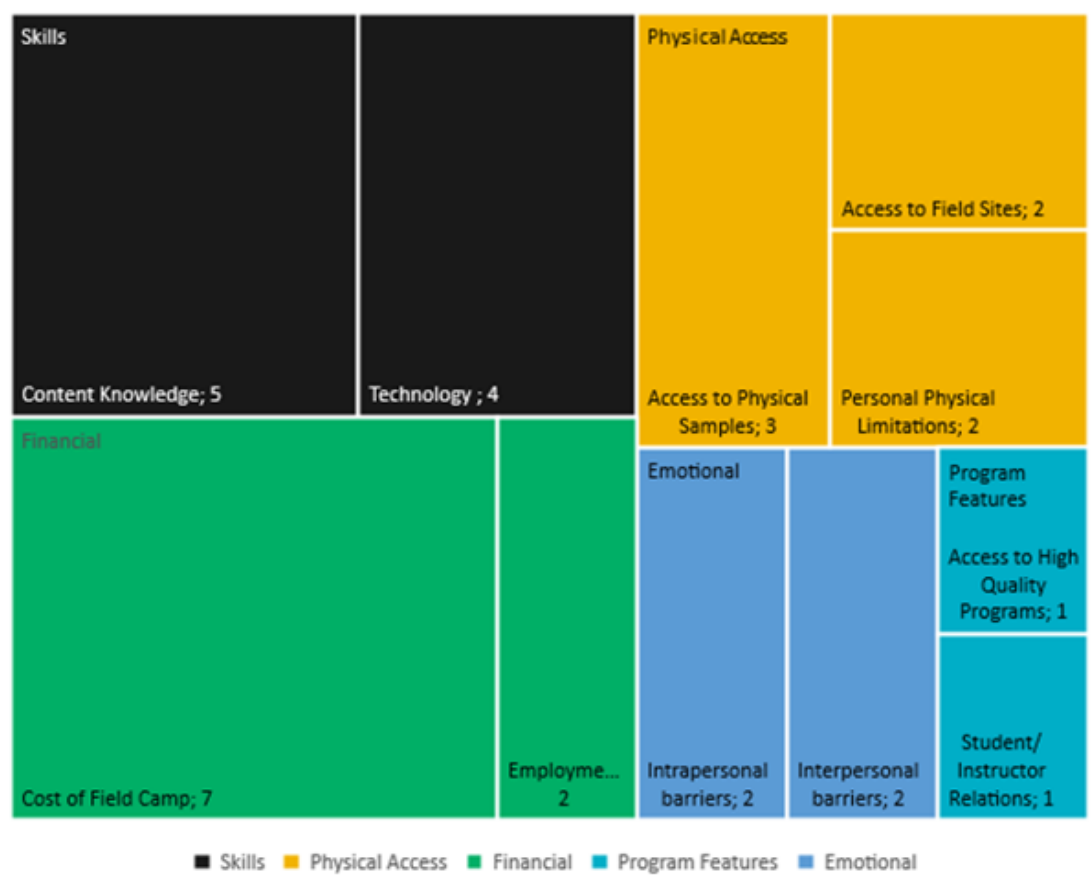

$\mathrm{n}=28$

$\mathrm{n}=$ number of comments

Figure 6. Prior to virtual field camp, students expressed their self-assessed barriers to success in the course.

- it helped me get familiar with the program a lot", and "I like this program. So much easier than doing it by hand." The "geoscience communication" theme developed through dialogue or observations of instructor interactions with students related to the course content and technology used for learning (e.g., Minecraft, Zoom, BbLearn). Subcodes of "technology" and "geology content knowledge" appeared within the theme, and we correlated NAGT LOs 5-6 with this theme. Example interactions of each included "I'm really sorry, I can only move up and down. Should I change the scale to be horizontal?", "You can't so just use these blocks to count up/down", "By up/down you mean left to right" [Instructor drew a picture.], "What makes you think it's a vein again?", "It's bluish-grey not the silvery grey - that's the argillite", "So what is the dark grey then?", "It's where you'll find your ore" [student points to another section], and "So, is that a vein?". The "team dynamics" theme presented in dialogue or observations of students demonstrating camaraderie and 


\section{$\underline{\text { Student identified common barriers to success-After Virtual Field Camp }}$}

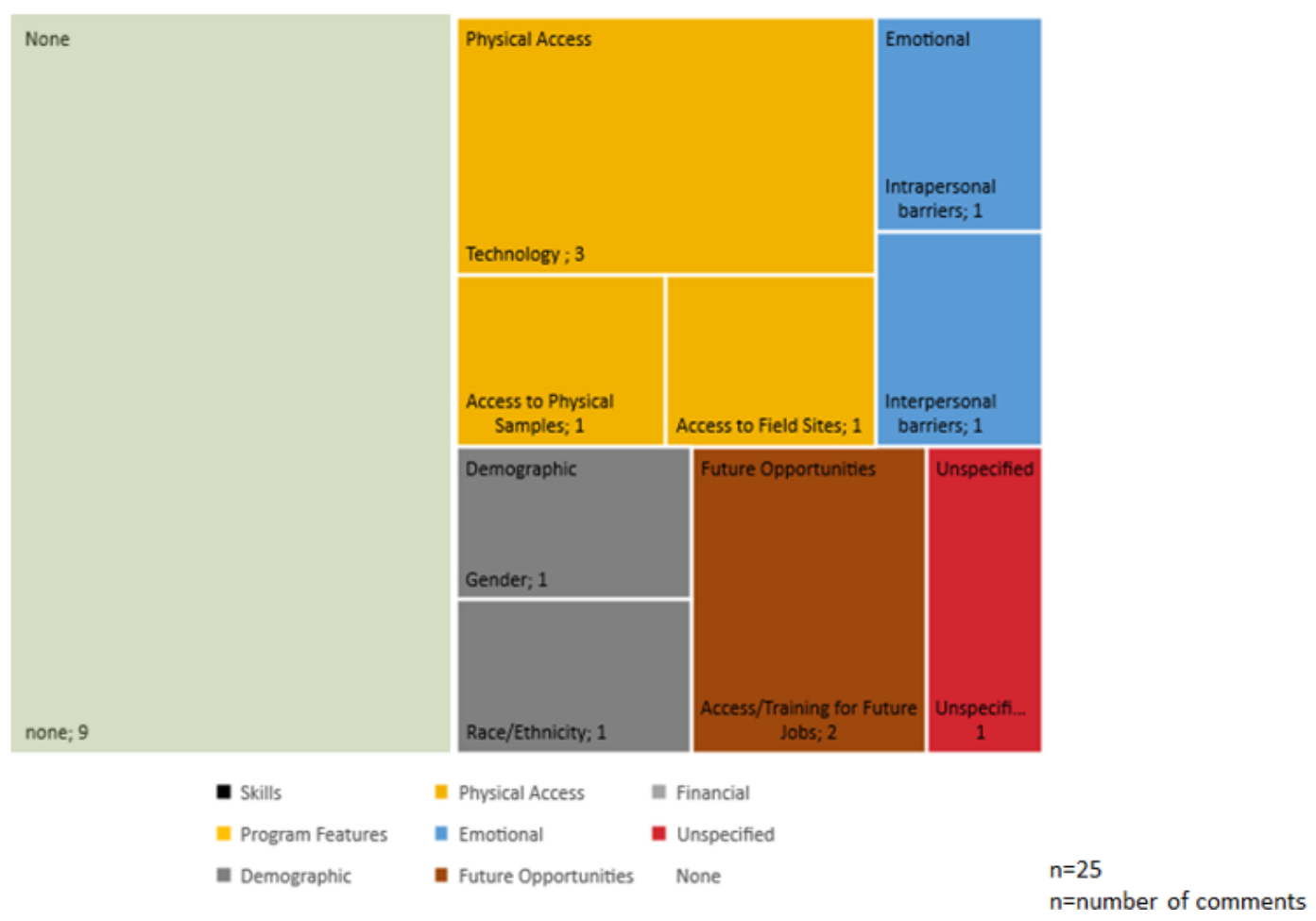

Figure 7. After completing virtual field camp, students had very different perceptions of barriers to succeeding in the field of geology.

fostering interpersonal relationships. Three subcodes originated within this theme: "using technology", "informal topics", and "future career plans". We correlated NAGT LO 7 with this theme. Examples of this theme included "I like to build the rooms bigger than they need to be so I don't feel claustrophobic", "Perfectly reasonable, gives you a better view, too", Back in breakout rooms and Minecraft (after lunch); server is not reset. It's K's birthday (everyone wishes student a happy birthday, and they discuss a lack of plans because of COVID), "Did you get your coffee today, G?", "I did, thank you!", "What about you, N? You looked pretty tired", "Yeah... just hadn't kicked in", and "I feel ya". The "barriers" theme encompassed dialogue or observations of students expressing adverse attitudes for the VFC. Four subcodes comprise this theme: "student emotions", "intellectual rigor", "time constraints", and "technology failures". We correlated NAGT LO 8 with this theme. Example expressions of each included "I got data overwhelmed", "We should have been warned that we would have to project downwards", "How do they expect us to get this done by lunch, we only have 30 minutes left", and server lost connection. The "motivation" theme consisted of dialogue or observations of students expressing positive emotions during learning activities. Subcodes of "geology identity", "future career plans", and "technology" captured the dimensions of this theme. We correlated NAGT LO 9 with this theme. Example observa- tions of each subcode included the following: when instructor asked if they feel like mining geologists, student answers "Heck, yeah!" "Honestly wouldn't mind doing this as a job" "Mmhmm, this would be a solid job" "But you'd be underground" "I wouldn't mind that" "I love the torch action here" "What?" "There's like some jump rope action going on with the torch shadows".

\section{Discussion}

\subsection{Developing geospatial skills}

Each of the exercises conducted in the VFC targeted specific concepts outlined in the recommended NAGT learning outcomes. We measured student geospatial skill improvement through 18 questions on the pre-survey and post-survey and found significant improvement in three learning outcomes.

The most significant improvement involved the "hydrocarbon project" exercise. We speculate that interpreting geophysical logs was a new concept for students, which was not taught in traditional geology core curriculum. This exercise was the students' first exposure to this method of assessing the subsurface. Thus, their skill improvement in this area was the most significant $(p=0.002$ and $p=0.008$ for identifying fining-upward and coarsening upward sequences, respectively). This exercise aligns with NAGT LO 3 and highlights 
Table 4. Relationship between the identified qualitative themes and the NAGT learning outcomes with examples of student comments or behaviors.

\begin{tabular}{|c|c|c|c|c|}
\hline Major theme & Major theme subcode & $\begin{array}{l}\text { NAGT learning } \\
\text { outcome }\end{array}$ & NAGT subcodes & Examples of NAGT learning outcome analysis \\
\hline \multirow{4}{*}{$\begin{array}{l}\text { Skill } \\
\text { development }\end{array}$} & \multirow{4}{*}{$\begin{array}{l}\text { geoscience content knowledge } \\
\text { technical knowledge }\end{array}$} & 1 & geologic knowledge & $\begin{array}{l}\text { "I'm just kind of excavating it to get a lay of the } \\
\text { land" }\end{array}$ \\
\hline & & 2 & geoscience skills & $\begin{array}{l}\text { "she said the scale is } 80 \% \text { ? It's true. I have to start } \\
\text { my map over. It's too large." }\end{array}$ \\
\hline & & 3 & $\begin{array}{l}\text { geoscience concept } \\
\text { comprehension }\end{array}$ & $\begin{array}{l}\text { [students] are unsure of the distance for the map and } \\
\text { are continuing to struggle with scale; student thinks } \\
\text { that } 6-7 \text { equals } 13 \text { blocks east or "face of pic [pic- } \\
\text { ture] to face of next pic" }\end{array}$ \\
\hline & & 4 & $\begin{array}{l}\text { reflexivity of } \\
\text { geoscience concepts }\end{array}$ & $\begin{array}{l}\text { [student] takes notice of fault placement and [a dif- } \\
\text { ferent student] confirms that "it continues through- } \\
\text { out" }\end{array}$ \\
\hline \multirow[t]{2}{*}{$\begin{array}{l}\text { Geoscience } \\
\text { communication }\end{array}$} & \multirow[t]{2}{*}{$\begin{array}{l}\text { using technology } \\
\text { geoscience content knowledge }\end{array}$} & 5 & argumentation & $\begin{array}{l}\text { Student thinks there may be "some sulfide in there, } \\
\text { doesn't look like a prominent vein to me" }\end{array}$ \\
\hline & & 6 & $\begin{array}{l}\text { explicit explanation of } \\
\text { understanding }\end{array}$ & $\begin{array}{l}\text { [students] debate rock types: "More orange" "Not } \\
\text { sure if discoloration" "Almost like azurite at the top } \\
\text { and becomes grey as you go down" "I'll just mark } \\
\text { it argillite" }\end{array}$ \\
\hline Team dynamics & $\begin{array}{l}\text { using technology } \\
\text { informal topics } \\
\text { future career plans }\end{array}$ & 7 & $\begin{array}{l}\text { interpersonal relation- } \\
\text { ships }\end{array}$ & $\begin{array}{l}\text { [students] have divided the tasks and will switch af- } \\
\text { ter lunch, sharing details to complete the respective } \\
\text { halves of the worksheet }\end{array}$ \\
\hline Barriers & $\begin{array}{l}\text { student emotions } \\
\text { intellectual rigor } \\
\text { time constraints } \\
\text { technology failures }\end{array}$ & 8 & $\begin{array}{l}\text { non-human educational } \\
\text { environment and peda- } \\
\text { gogy }\end{array}$ & $\begin{array}{l}\text { "How do they expect us to get this done by lunch, } \\
\text { we have only } 30 \text { min left" }\end{array}$ \\
\hline $\begin{array}{l}\text { Professional } \\
\text { motivation }\end{array}$ & $\begin{array}{l}\text { geoscience identity } \\
\text { future career plans } \\
\text { technology }\end{array}$ & 9 & workload & $\begin{array}{l}\text { "Honestly wouldn't mind doing this as a job" } \\
\text { "Mmhmm, this would be a solid job" "But you'd } \\
\text { be underground" "I wouldn't mind that" }\end{array}$ \\
\hline
\end{tabular}

that a virtual field camp can provide opportunities to gather and interpret data to explain the geologic history of an area in a spatial sense.

Another question aligned with NAGT LO 3 challenged students to use the principle of superposition, interpret bedding orientation (strike and dip), and map patterns related to topography. A related question asked students to choose an area on the same map to collect more data. We scored this question based on the quality of thought process leading to their decisions and the data they felt they needed to acquire to answer their questions. This structuring of tasks reinforced the concept that we usually have limited time and funding to map areas and how important it is to prioritize complicated areas in your map. Interestingly, the accompanying question indicated that students showed little improvement on prioritizing a mapping area to gather more data $(p=1)$. This may be due to an ambiguous design of the question, or the students already had a good understanding of this particular topic which left little room for improvement.

Further, these results also show that students drastically improved ( $p=0.027)$ their ability to plot location and structural data on a map using appropriate symbology. Even with the additional learning of how to move and manipu- late avatars in Minecraft, students improved their ability to produce correct geologic maps. This assessment aligns with NAGT LO 2 and portrays how students can improve on the same skills in a virtual world as they would in a traditional in-the-field experience.

Lastly, students significantly improved $(p=0.009)$ in their ability to describe characteristics of rocks and distinguish between units in the field. We emphasized rock characteristics in the Google Earth exercise by incorporating outcrop and hand sample photographs and the Block Minecraft Mountain lesson using facies mapping, and this improvement ranks second in greatest gains made during the VFC, aligning with NAGT LO 4. Three design considerations helped students improve on compiling multiple lines of data to develop their best interpretation of the mapping area: providing partially distributed photos of rocks, situating the exercise alongside three-point problem orientation data and recognition of structures, and requiring students to develop hypotheses of the units in which they could belong.

Notably, students' ability to deduce an area's geologic history showed less significant improvement $(p=0.477)$ than most other skills. For example, a question assessing this skill asked students, "Which of the following events occurred or 
did not occur (metamorphism, erosion, faulting, etc.)?" We postulate that the relatively high $p$ value here reflects extensive exposure to this topic in core geology curriculum; thus, students already achieved high marks on the pre-test.

\subsection{Strength of combined technologies}

\subsubsection{Augmented spatial exploration}

Instead of thinking of Minecraft as a replacement for an in-the-field experience, we came to see it as a tool to enhance students' understanding of complex spatial patterns. In this way, the design of the VFC illustrates the connectivism principle in Siemens (2005) that learning can reside in nonhuman appliances - in this case, a virtual representation of the world.

The typical exercises practiced in traditional field camps include measuring stratigraphic columns, logging cores, correlating geophysical and geochemical logs, and bedrock mapping. These tasks aim to teach students what the subsurface looks like in the field but are constrained by location with minimal data to consider. In essence, students receive an obscured snapshot. Our VFC allowed students to engage in a wide variety of field experiences, taking advantage of situations inaccessible to uninsured workers, such as being in an active mine shaft, or inaccessible to humans at all, such as flying through underground layers of see-through folded strata. These unique perspectives provided a broader view of the geosciences or a panoramic portrait. Further, qualitative data indicated minimal technology barriers, such as translating spatial relationships between realities, dropped internet connection, or being distracted by the virtual technologies.

Combining technologies proved key to the virtual camp design and experiencing tasks from an industry perspective. However, Minecraft has an advantage over other 3D virtual platforms, such as Unity, due to the ability for students to excavate into the subsurface. Students dug for treasure, prospected for silver, and drilled for oil using the same data sets and software they will be using in geoscience careers. The reward of confirming one's hypothesis after developing a model using subsurface geologic data goes beyond what students can do in a traditional field camp and contributes to motivation, encouraging students to keep learning. For example, several of the statements coded to the "motivation" theme conveyed genuine enthusiasm and excitement, such as feeling like mining geologists and appreciating the site environment (torches).

Siemens (2005) argued within connectivism that decisionmaking is essential in the learning process and stimulates motivation. The situated problems of the VFC highlight the value of what Downes (2020) described as allowing students to experience the need to make new connections continuously. Such a structure contributed to a self-perpetuating cycle feeding intrinsic motivation and supporting continual learning (Smidt et al., 2017).
Overall, student responses on the SIS-M indicate successful triggering and maintaining of interest. Students were more likely to be undecided with respect to maintaining interest. However, a lack of preference for online learning or Minecraft supports using integrated technologies and careful design to engage learners successfully.

\subsubsection{Custom accommodations}

Learner preferences, needs, and experiences influence the demand for differentiation and flexibility. This has always been a point of discussion with regards to field camp and students with mobility issues. A virtual camp eliminates this barrier completely; however, the format of our virtual camp allowed for some additional flexibility. Minecraft provides a sandbox environment where students can, for example, modify the look and sound of the game to assist with visual or auditory limitations. In the field, time also presents a constraint as learners work at different paces. The VFC allowed students to complete field tasks in their own time rather than racing the clock to finish before sunset. Custom accommodations also become possible in a virtual sandbox. For example, one team of students wanted to track progress, requesting inworld signs to help with on-screen annotations. Another student requested a set of stairs to view the sloped outcrops more clearly, and another expressed appreciation for being able to customize a dig site, mitigating a claustrophobic sensation. Similarly, mistakes could easily be corrected as travel time in-world is significantly shorter, facilitating quick or frequent check-ins as observed among all three teams. Even the most enthusiastic and energetic students may experience frustration returning to a location in a traditional field camp; however, there were many instances in the VFC where students voluntarily retraced their steps in the Minecraft worlds.

Connectivism recognizes autonomy and diverse processes in learning networks (Downes, 2008). Autonomy is also inextricably intertwined in decision-making, and designing for scaffolded autonomy is challenging. The selection of a sandbox gaming environment and problem-based learning to embody multiple aspects of the theoretical framework facilitated the successes identified in the VFC. Situating problems within authentic contexts contributed to critical thinking and metacognitive self-regulation gains (Stefanou et al., 2013). The integrated design contributed to integrated positive impacts identified in student achievement and perceptions of experiences.

\subsubsection{Communication}

Minecraft and the use of other virtual teaching tools also afford a different approach to visual and verbal communication as students worked together in the field. They could see each other in-world, quickly locating one another and what outcrop or topographic feature they referred to when discussing the project. Being logged in to platforms simulta- 
neously allowed team members to communicate verbally in Zoom and share notes, images, and other files via Discord. Video capabilities allowed students to show each other their maps while screen sharing to discuss location of contacts, and audio conversations did not interfere with in-world navigation or mapping, both hand-intensive activities. Text-based chatting supplemented audio and video interactions. Students chose which channels to engage and when contributing to autonomous support and agency. For some students, multimodal communication mitigated technology barriers such as poor connection or low-quality camera.

Self-regulation is essential for success in online learning environments (Wang et al., 2013). However, a primary criticism of connectivism lies in the unrealized potential to foster self-regulation through agency and autonomy in communication (Downes, 2020). The flexibility and integration of communication platforms meant that students could choose which system suited their needs best.

\subsection{Successfully recreating field experiences}

Traditional field camps include non-academic content and experiences, such as practicing team building, managing time, and socializing. Consider the team of students who notice a storm on the horizon and quickly modify plans to finish a ridge traverse before lightning begins. These students then share their experience with other teams as they collectively reflect on the day's events over dinner. Navigating these social interactions in the field provides an invaluable contribution to professional identity formation (Streule and Craig, 2016). We found that students in our VFC encountered the same interactions and barriers as a traditional field camp (emotions, intellectual rigor, time constraints), team building through geologic and informal discussions, and motivation to continue pursuing a career in geology because of a positive experience in the field.

The VFC instructors intentionally promoted an inclusive learning environment by allowing students to self-select how they wanted to be seen by their peers with their avatar identities, not requiring video communication, and guiding a discussion on racism and discrimination within the geosciences. These purposeful decisions must be made in online learning environments and provide an opportunity to include learners with disabilities, life challenges, and other factors that typically prevent their participation or adversely impact success in traditional field camps.

Other unique virtual benefits included less time organizing field logistics, decreased travel time and financial burdens for participants, more time allotted for covering content, and opportunities for directly connecting geology skills to potential career pathways. In terms of negative impacts, only three students commented that they did not feel connected to the experience or that the experience was inferior to a traditional camp. Notably, the combination of tools and autonomous decisions available to students did not mitigate challenges with gender dynamics, as evidenced in one post-survey comment. Future research on virtual field experiences might capitalize on these findings by investigating the value of these benefits or the nuances of negative impacts and how to mitigate these challenges.

\subsection{Challenges and further development}

After running the VFC, we confirmed that the delivery method proved to be a major limitation. Minecraft graphics are simple by design to allow for the full participation of players with low internet bandwidth. While the decision to use the game mitigated a technology barrier, it presents an additional limiting factor when presenting realistic rock textures. We note that the sandbox design of Minecraft affords the use of more realistic and variable rock texture, but adding additional graphics slows down the initial load speed for the world, amplifying a technology barrier. As discussed earlier, technology presented a barrier in the VFC design. Some students expressed their frustrations about technology issues, such as being kicked off the server or dropped from the video call. However, the instructional team anticipated these challenges and were able to address technology issues quickly, minimizing the potential negative impact.

Field camp is often an immersive experience that forces students to disengage from their home life because of the travel component. While being home with family was a benefit for some students, it served as a distraction for others. Although there were no significant performance or motivation impacts, some students experienced frequent disruptions and struggled to schedule the VFC around their jobs and family responsibilities. Virtual field experiences must provide additional guidance for learners about how to balance expectations and workloads.

\section{Conclusion}

We created five worlds in Minecraft targeting the nine NAGT learning outcomes designing field experiences. Each of these worlds had realistic topography and vegetation to trigger learners' interest and engage them in a virtual simulation. We paired two of these worlds with subsurface datasets and based two worlds on the Block Mountain and Rochester Creek field localities outside Dillon, MT, for an authentic problem-based context. We used three industry-standard software programs (Google Earth, Leapfrog, and Imago) to incorporate geologic datasets into subsurface exploration and reconnaissance mapping, exposing students to authentic professional activities.

The small sample size of this study and substitution design of the field experience limit the interpretation and generalization of these findings. However, students learned targeted fundamental geologic skills, which we assessed as level of improvement. The areas where students improved the most included NAGT LOs 2, 3, and 4. The game successfully 
triggered the interest of students but posed limited barriers to engagement. Further, students experienced many of the same subject matter challenges, revelations, and rewards as a traditional field camp. Integrating career-specific training and authentic components of the project also contributed to the motivation observed during field experiences. Overall, a Minecraft-themed virtual field camp achieved the curricular goals and is an effective tool to teach subsurface geologic patterns to students with barriers to a traditional field camp, or more specifically, it is effective as a preparatory experience to maximize the learning in a traditional camp.

Code availability. The source codes used in this paper are available in Godfirnon et al. (2020, http://hdl.handle.net/2268/ 251387, last access: 30 September 2021), Jamieson and Herman (2019, http://www.impacttectonics.org/GeoTools/3ppops.html, last access: 30 September 2021), Mapzen (2017, https://tangrams. github.io/heightmapper/\#12.6875/45.4652/-112.5559, last access: 30 September 2021), MightyPork (2018, https://mcrpw.github. io/, last access: 30 September 2021), Mineshopper (2019, https://www.carpentersblocks.com/, last access: 30 September 2021), MrCrayfish (2020, https://mrcrayfish.com/tools?id=, last access: 30 September 2021), World Painter (2020, https://www. worldpainter.net/, last access: 30 September 2021), Tryashtar (2020, https://github.com/tryashtar/image-map, last access: 30 September 2021), and Whitmeyer (2021, http://csmgeo.csm.jmu.edu/geollab/ Whitmeyer/web/visuals/GoogleEarth/tools/SD.html, last access: 30 September 2021).

Video supplement. Several videos that illustrate student behavior in the Minecraft game can be found at this YouTube link: https://www.youtube.com/playlist?list= PLaHjgfz6eINe9UgTT9tZs7ZAb9nvn810J (last access: 5 October 2021, Rader, 2021).

Author contributions. The course was developed by ER and RL. The education research was conducted by DR, TAD, and NW. All authors contributed to the writing of the manuscript.

Competing interests. The contact author has declared that neither they nor their co-authors have any competing interests.

Disclaimer. Publisher's note: Copernicus Publications remains neutral with regard to jurisdictional claims in published maps and institutional affiliations.

Special issue statement. This article is part of the special issue "Virtual geoscience education resources". It is not associated with a conference.
Acknowledgements. This work was supported by an award from NASA's SSERVI (Solar System Exploration Research Virtual Institute) to principal investigator Jennifer Heldmann (NASA Ames Research Center) for the FINESSE and RESOURCE projects. Support for the development of this course came from the University of Idaho College of Science and the Geology Department. The two teaching assistants, Emily Forsberg and Nolan Blackford, were critical to the successful rollout of this course.

Financial support. This research has been supported by the National Aeronautics and Space Administration (grant no. SSERVI).

Review statement. This paper was edited by Steven Whitmeyer and reviewed by William Parcell and one anonymous referee.

\section{References}

Anandapadmanaban, E., Tannady, J., Norheim, J., Newman, D. J., and Hoffman, J. A.: Holo-SEXTANT: An augmented reality planetary EVA navigation interface, in: Proceedings of the 48th International Conference on Environmental Systems, Albuquerque, USA, 8-12 July 2018, 264, 2018.

Angrosino, M. V.: Naturalistic observation, Left Coast Press, Inc., Walnut Creek, USA, 2007.

Barnes, R., Gupta, S., Traxler, C., Ortner, T., Bauer, A., Hesina, G., Paar, G., Huber, B., Juhart, K., Fritz, L., Nauschnegg, B., Muller, J.-P., and Tao, Y.: 2018 Geological analysis of Martian rover-derived digital outcrop models using the 3-D visualization tool, planetary robotics 3-d viewer - PRo3D, Earth Space Sci., 5, 285-307, https://doi.org/10.1002/2018EA000374, 2008.

Black, A. A.: Spatial ability and earth science conceptual understanding, J. Geosci. Educ., 53, 402-414, https://doi.org/10.5408/1089-9995-53.4.402, 2005.

Bursztyn, N., Sajjadi, P., Riegel, H., Huang, J., Wallgrün, J. O., Zhao, J., Masters, B., and Klippel, A.: Virtual strike and dip Advancing inclusive and accessible field geology, Geosci. Commun. Discuss. [preprint], https://doi.org/10.5194/gc-2021-16, in review, 2021.

Campbell, B., Collins, P., Hadaway, H., Hedley, N., and Stoermer, M.: Web3D in ocean science learning environments: Virtual big beef creek, in: Proceedings of the 7th International Conference on 3D Web Technology, Web3D '02, Tempe, USA, 24 February 2002, 85-91, https://doi.org/10.1145/504502.504517, 2002.

Carabajal, I. G., Marshall, A. M., and Atchison, C. L.: A synthesis of instructional strategies in geoscience education literature that address barriers to inclusion for students with disabilities, J. Geosci. Educ., 65, 531-541, 2017.

Clemenson, G. D., Henningfield, C. M., and Stark, C. E. L.: Improving hippocampal memory through the experience of a rich minecraft environment, Front. Behav. Neurosci., 13, 57, https://doi.org/10.3389/fnbeh.2019.00057, 2019.

Creswell, J. W., Plano Clark, V. L., Gutmann, M. L., and Hanson, W. E.: Advanced mixed methods research designs, in: Handbook of mixed methods in social and behavioral research, edited by: Tashakkori, A. and Teddlie, C., Sage, Thousand Oaks, USA, 209-240, 2003. 
Dishion, T. J. and Granic, I.: Naturalistic observation of relationship processes, in: Comprehensive handbook of psychological assessment, edited by: Hayes S. N. and Heiby, E. M., John Wiley \& Sons, Inc., Hobokun, USA, 143-161, 2004.

Dousay, T. A.: Effects of redundancy and modality on the situational interest of adult learners in multimedia learning, Educ. Technol. Res. Dev., 64, 1251-1271, https://doi.org/10.1007/s11423-0169456-3, 2016.

Dousay, T. A. and Trujillo, N. P.: An examination of gender and situational interest in multimedia learning environments, Br. J. Educ. Technol., 50, 876-887, https://doi.org/10.1111/bjet.12610, 2019.

Downes, S.: Places to go: Connectivism \& connective knowledge, Innov. J. Online Educ., 5, 1-8, available at: https://nsuworks. nova.edu/cgi/viewcontent.cgi? article $=1037 \&$ context=innovate (last access: 30 September 2021), 2008.

Downes, S.: Recent work in connectivism, EURODL, 22, 113-132, https://doi.org/10.2478/eurodl-2019-0014, 2020.

Elgner, S., Adeli, S., Gwinner, K., Preusker, F., Kersten, E., Matz, K.-D., Roatsch, T., Jaumann, R., and Oberst, J.: Visualizing planetary data by using 3D engines, European Planetary Science Congress, Riga, Latvia, 17-22 September 2017, 11, 2017.

Entwisle, D.: 3D geological modelling at the British Geological Survey (BGS), NTU-BCA Workshop on 3D Geological Modelling, Singapore, 17 January 2019, 522402, available at: http: //nora.nerc.ac.uk/id/eprint/522402/ (last access: 30 September 2021), 2019.

Feig, A. D., Atchison, C. L., Stokes, A., and Gilley, B.: Achieving inclusive field-based education: Results and recommendations from an accessible geoscience field trip, J. SoTL, 19, 66-87, https://doi.org/10.14434/josotl.v19i1.23455, 2019.

Fleischner, T. L., Espinoza, R. E., Gerrish, G. A., Greene, H. W., Kimmerer, R. W., Lacey, E. A., Pace, S., Parrish, J. K., Swain, H. M., Trombulak, S. C., Weisberg, S., Winkler, D. W., and Zander, L.: Teaching biology in the field: Importance, challenges, and solutions, BioSci., 67, 558-567, https://doi.org/10.1093/biosci/bix036, 2017.

Formosa, S.: Neogeography and preparedness for real-to-virtual world knowledge transfer: Conceptual steps to Minecraft Malta, Future Internet, 6, 542-555, https://doi.org/10.3390/fi6030542, 2014.

Godfirnon, M., Pirard, E., Evrard, M., Barnabé, P., and Shikika, A.: BetterGeoEdu: European project for popularizing science through video games, ORBi [code], available at: http://hdl. handle.net/2268/251387 (last access: 30 September 2021), 2020.

Gregory, D. D., Tomes, H. E., Panasiuk, S. L., and Andersen, A. J.: Building an online field course using digital and physical tools including VR field sites and virtual core logging, J. Geosci. Educ., 1-16, https://doi.org/10.1080/10899995.2021.1946361, 2021.

Hidi, S. E. and Harackiewicz, J. M.: Motivating the academically unmotivated: a critical issue for the 21 st century, Rev. Educ. Res., 70, 151-179, 2000.

Hodges, K. V. and Schmitt, H. H.: Imagining a new era of planetary field geology, Sci. Adv., 5, 4-6, https://doi.org/10.1126/sciadv.aaz2484, 2019.

Iwahashi, J., Nishioka, Y., Kawabata, D., Ando, A., and Une, H.: Development of an online learning environment for geography and geology using Minecraft, Abstracts of the ICA, Tokio,
Japan, 15-20 July 2019, https://doi.org/10.5194/ica-abs-1-1432019, 2019.

Jamieson, J. and Herman, G.: Dynamic 3-Point Geological Plane Solver, Geologic Web Utilities [code], available at: http: //www.impacttectonics.org/GeoTools/3ppops.html (last access: 30 September 2021), 2019.

Kop, R.: The challenges to connectivist learning on open online networks: Learning experiences during a massive open online course, Int. Rev. Res. Open Dis. Learning, 12, 19-38, https://doi.org/10.19173/irrodl.v12i3.882, 2011.

Lambert, D. and Reiss, M.: The place of fieldwork in geography and science qualifications, University of London, London, UK, 2014.

Liben, L. S. and Titus, S. J.: The importance of spatial thinking for geoscience education: Insights from the crossroads of geoscience and cognitive science, Special Paper of the Geol. Soc. Am., 486, 51-70, https://doi.org/10.1130/2012.2486(10), 2012.

Mapzen: Tangram Heightmapper, Github [code], available at: https://tangrams.github.io/heightmapper/\#12.6875/45.4652/ -112.5559 (last access: 30 September 2021), 2017.

Marín-Spiotta, E., Barnes, R. T., Berhe, A. A., Hastings, M. G., Mattheis, A., Schneider, B., and Williams, B. M.: Hostile climates are barriers to diversifying the geosciences, Adv. Geosci., 53, 117-127, https://doi.org/10.5194/adgeo-53-117-2020, 2020.

MightyPork: Resource Pack Workbench, Github [code], available at: https://mcrpw.github.io/ (last access: 30 September 2021), 2018.

Mineshopper: Carpenter's Blocks, Carpenter Blocks [code], available at: https://www.carpentersblocks.com/ (last access: 30 September 2021), 2019.

Minocha, S., Tilling, S., and Tudor, A.-D.: Role of virtual reality in geography and science fieldwork education, Knowledge Exchange Seminar Series, Learning from New Technology, available at: https://kess.org.uk/2018/05/02/prof-shailey-minochadr-ana-despina-tudor-ou-role-virtual-reality-geography-sciencefieldwork-education/ (last access: 30 September 2021), 2018.

Montello, D. R.: Spatial information theory: Foundations of geographic information science, Springer Nature, Basingstoke, UK, 2001.

Moore, K., Dykes, J., and Wood, J.: Using Java to interact with georeferenced VRML within a virtual field course, Comp. Geosci., 25, 1125-1136, https://doi.org/10.1016/S0098-3004(99)000850,1999 .

MrCrayfish: MrCrayfish's Model Creator, MrCrayfish [code], available at: https://mrcrayfish.com/tools?id=mc (last access: 30 September 2021), 2020.

Nebel, S., Schneider, S., and Rey, G. D.: Mining learning and crafting scientific experiments: A literature review on the use of Minecraft in education and research, J. Educ. Technol. Soc., 19, 355-366, 2016.

Orion, N., Ben-Chaim, D., and Kali, Y.: Relationship between earthscience education and spatial visualization, J. Geosci. Educ., 45, 129-132, https://doi.org/10.5408/1089-9995-45.2.129, 1997.

Ortner, T., Haaser, G., Steinlechner, H., Barnes, R., Gupta, S., Traxler, C., and Paar, G.: Immersive visualization of planetary reconstructions for geological interpretation, European Planetary Science Congress 2018, Berlin, Germany, 16-21 September 2018, 12, 2018. 
Parcell, W. and Parcell, A.: A FIELD CAMP EXPERIENCE WITH MINECRAFT: GAMIFYING FIELD MAPPING, EXPLORATION, AND DISCOVERY IN THE BIGHORN BASIN, WYOMING, Geological Society of America Abstracts with Programs, Virtual, https://doi.org/10.1130/abs/2020AM-356089, 2020.

Poland, R., Baggott, L., and Nichol, J.: The Virtual Field Station (VFS): Using a virtual reality environment for ecological fieldwork in A-level biological studies - Case 3, British J. Educ. Technol., 34, 215-231, https://doi.org/10.1111/14678535.00321, 2003.

Rader, E.: Pandemic Minecrafting, YouTube, available at: https://www.youtube.com/playlist?list= PLaHjgfz6eINe9UgTT9tZs7ZAb9nvn810J, last access: 5 October 2021.

R Core Team: R: A language and environment for statistical computing, R Foundation for Statistical Computing, available at: https://www.r-project.org/, last access: 30 September 2021.

Riordan, B. C. and Scarf, D.: Crafting minds and communities with Minecraft, F1000Research, 5, 2339, https://doi.org/10.12688/f1000research.9625.1, 2016.

Sahin, E. Ç. and Ozgur, D.: Landscape awareness of childhood in computer games: In the case of "Minecraft", J. Digi. Landscape Archit., 1, 316-326, https://doi.org/10.14627/537612036, 2016.

Scarlett, M.: Gaming geography: Using Minecraft to teach essential geographic skills, Society for Information Technology \& Teacher Education International Conference, San Diego, USA, 11-15 April 2015, 838-840, 2015.

Short, D.: Teaching scientific concepts using a virtual world: Minecraft, Teaching Science, 58, 55-58, 2012.

Siemens, G.: Connectivism: A learning theory for the digital age, Intnl. J. Instruc. Technol. Dist. Learn., Vol. 2, available at: http://www.itdl.org/Journal/Jan_05/article01.htm (last access: 30 September 2021), 2005.

Smidt, H., Thornton, M., and Abhari, K.: The future of social learning: A novel approach to connectivism, Proceedings of the 50th Hawaii International Conference on System Sciences, Waikoloa Village, USA, 3-6 January 2017, 2116-2125, https://doi.org/10.24251/hicss.2017.256, 2017.

Sorby, S. A.: Improving the spatial skills of engineering students: Impact on graphics performance annd retention, Eng. Des. Graph. J., 65, 31-36, 2001.

Stefanou, C., Stolk, J. D., Prince, M., Chen, J. C., and Lord, S. M.: Self-regulation and autonomy in problem- and project-based learning environments, Active Learn. in High Educ., 14, 109122, https://doi.org/10.1177/1469787413481132, 2013.
Steuer, S. and Thorpe, S.: Let's play - the use of Minecraft ${ }^{\circledR}$ to communicate the complexity of the deep subsurface to the public, American Geophysical Union Fall 2019 Meeting, San Francisco, USA, 9-13 December 2019, available at: https://ui.adsabs. harvard.edu/abs/2019AGUFMED14B..05S/abstract (last access: 30 september 2021), 2019.

Streule, M. J. and Craig, L. E.: Social learning theories-an important design consideration for geoscience fieldwork, J. Geosci. Educ., 64, 101-107, https://doi.org/10.5408/15-119.1, 2016.

Titus, S. and Horsman, E.: Characterizing and improving spatial visualization skills, J. Geosci. Educ., 57, 242-254, https://doi.org/10.5408/1.3559671, 2009.

Trujillo, N. P. and Dousay, T. A.: An examination of gender and situational interest in multimedia learning environments [Poster], College of Education Research Symposium, Laramie, USA, 7 March 2014.

Tryashtar: Image Map, Github [code], available at: https://github. com/tryashtar/image-map (last access: 30 September 2021), 2020.

Vitacion, R. and Liu, L.: Procedural generation of 3D planetaryscale terrains, Pasadena, USA, 30 July-1 August 2019, SMCIT 2019, 70-77, https://doi.org/10.1109/SMC-IT.2019.00014, 2019.

Wang, C.-H., Shannon, D. M., and Ross, M. E.: Students' characteristics, self-regulated learning, technology self-efficacy, and course outcomes in online learning, Dist. Educ., 34, 302-323, https://doi.org/10.1080/01587919.2013.835779, 2013.

Whitmeyer, S. J.: Orientation symbol generator, Whitmeyer [code], available at: http://csmgeo.csm.jmu.edu/geollab/Whitmeyer/ web/visuals/GoogleEarth/tools/SD.html, last access: 30 September 2021.

Whitmeyer, S. J. and Dordevic, M.: Creating virtual geologic mapping exercises in a changing world, Geosphere, 17, 226-243, 2021.

World Painter: Pepsoft, World Painter [code], available at: https: //www.worldpainter.net/ (last access: 30 September 2021), 2020.

Zhao, J., Wallgrün, J. O., LaFemina, P. C., DiBiase, R. A., Carr, J. C., and Klippel, A.: Toward a universal workbench for visualization and quantitative exploration of earth science data in immersive virtual reality, Fall Meeting of American Geophysical Union, Washington D.C., USA, 10-14 December 2018, 2018. 